Jeremy J. Ramsden

\title{
What is sustainability?
}

ABSTRACT. The goal of this essay is to define sustainability. Existing usage is examined and two distinct, though interrelated in complex ways, categories are identified: environmental and industrial (or commercial) sustainability. Although in the long term industrial sustainability depends on environmental sustainability (since evidently industry cannot continue if humans do not survive), in the short term achievement of the former is inimical to the latter. The accumulation of knowledge enables local action in favour of both types of sustainability to be undertaken but although the problems of unsustainability are recognized as being of global extent, practical ways of tackling them at the global level have not yet been devised. The overwhelming course of environmental unsustainability emerges as population growth multiplied by increasing per capita demands, both of which are required by industrial sustainability according to our present economic model. The challenge, therefore, is to find out how mankind can continue to develop while keeping a relatively stable world population much lower than the present one and according less weight to purely material goods.

Nanotechnology Perceptions 6 (2010) 179-195

Nonsubscribers: purchase individual article 